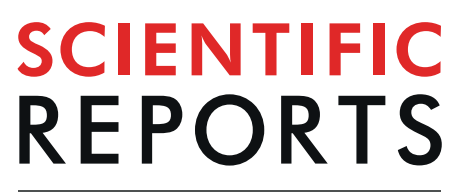

natureresearch

\title{
Return to work and clinical outcome after surgical treatment and conservative management of patients with intramedullary spinal cord ependymoma
}

\begin{abstract}
Bedjan Behmanesh ${ }^{*}$, Florian Gessler, Sae-Yeon Won, Daniel Dubinski, Johanna Quick-Weller,
\end{abstract} Lioba Imoehl, Volker Seifert \& Gerhard Marquardt

The ability to return to work after treatment of diseases is an important issue. Aim of this study is to compare surgery and conservative management focusing on clinical outcome and ability to return to work in patients with intramedullary spinal cord ependymoma. Retrospective, single center study. The neurological status at first presentation, as well as in long-term follow-up, were assessed using the modified McCormick Disability Scale and modified Rankin Scale. The study population consisted of 56 patients, $23(41 \%)$ were managed conservatively and $33(59 \%)$ underwent microsurgical resection. The median age was 47.5 years in the conservative group and 44.5 in the surgical group. At first admission 18 of conservatively treated and 28 of surgically treated patients were employed, $p=0.7$. At the last follow-up 15 (83\%) of conservatively and $10(36 \%)$ of surgically treated patients returned to work, $p=0.002$. The median modified McCormick score in both groups (conservative vs. surgical) was at admission 1 vs. $1, p=1.0$ and at last follow up 1 vs. $2.5, p=0.001$. Patients clinical outcome in the surgical group was significantly reduced at last follow up as assessed by the modified Rankin Scale (mRs score of $0-2$ ) at admission $100 \%$ vs. $100 \%$ and last follow-up $94 \%$ vs. $57 \%, p=0.007$. In our investigated study population, conservatively managed patients revealed a significantly better outcome and were more often able to return to work.

According to the results of a survey from 2015 among the German population in the age between 18 and 60 years, work and being employed ranged as an important factor of quality of life after family and partnership ${ }^{1}$. Being employed is synonymous with a normal life and is regarded as a marker of complete recovery after treatment of several diseases. Moreover, employment provides a sense of structure, income and identity ${ }^{2,3}$. Until now many data have been published analyzing and assessing treatment approaches and the effect of surgery on patient's outcome, but few data exist evaluating patients' outcome after conservative management ${ }^{4-8}$. To the best of our knowledge no data have been published with focus on work ability and return to work after treatment, either surgical or conservative management of patients with intramedullary spinal cord ependymoma.

\section{Results}

The study cohort included 56 patients with a median age of $51 \pm 13.8$ years. The gender distribution included $24(42.9 \%)$ females and $32(57.1 \%)$ males. Subsequently 33 (58.9\%) patients underwent surgery and $23(41.1 \%)$ preferred conservative management with follow-up examination and MRI. At first admission 28 (84.8\%) from 33 patients with recommendation for surgery and $18(78.3 \%)$ from 23 patients from the conservatively treated group were in working age and were then included in this study. Table 1 entails further patients data.

Surgical group. Twenty eight of 33 subsequently surgically treated patients were employed at first admission. The median age in this group was $44.5 \pm 10.5$ years with a gender distribution of $10(35.7 \%)$ females and 


\begin{tabular}{|c|c|c|c|}
\hline Characteristics & $\begin{array}{l}\text { conservatively } \\
\text { managed }\end{array}$ & $\begin{array}{l}\text { surgically } \\
\text { treated }\end{array}$ & Pvalue \\
\hline No. patients & 23 & 33 & \\
\hline $\begin{array}{l}\text { No. patients in } \\
\text { working age }\end{array}$ & $18(78.3 \%)$ & $28(84.8 \%)$ & 0.7 \\
\hline Age (mean) & $47.5 \pm 10.5$ years & $\begin{array}{l}44.5 \pm 10.5 \\
\text { years }\end{array}$ & 0.3 \\
\hline \multicolumn{4}{|l|}{ Sex } \\
\hline Male & $9(\%)$ & 18 & 0.4 \\
\hline Female & $9(\%)$ & 10 & \\
\hline $\begin{array}{l}\text { Follow Up (mean/ } \\
\text { range) }\end{array}$ & $\begin{array}{l}53.5(4-118) \\
\text { months }\end{array}$ & $\begin{array}{l}81.8(3-266) \\
\text { months }\end{array}$ & 0.4 \\
\hline \multicolumn{4}{|l|}{ Location } \\
\hline Cervical & 12 & 13 & 0.2 \\
\hline Thoracic & 6 & 12 & 0.6 \\
\hline Cervicothoracic & & 2 & \\
\hline Conus & & 1 & \\
\hline \multicolumn{4}{|l|}{ Involved levels } \\
\hline 1 & 14 & 20 & 0.7 \\
\hline$>1$ & 4 & 8 & 0.7 \\
\hline \multicolumn{4}{|l|}{ Initial symptoms } \\
\hline Pain & 2 & 5 & 0.7 \\
\hline Paresthesia & 11 & 4 & 0.002 \\
\hline Pain + Paresthesia & 0 & 13 & 0.0005 \\
\hline Motor weakness & 1 & 3 & 1.0 \\
\hline No symptoms & 4 & 1 & 0.07 \\
\hline other & 0 & 2 & 0.5 \\
\hline $\begin{array}{l}\text { Duration of symptoms } \\
\text { average (range) }\end{array}$ & $\begin{array}{l}10.6(1-48) \\
\text { months }\end{array}$ & $\begin{array}{l}11.9(1-48) \\
\text { months }\end{array}$ & \\
\hline \multicolumn{4}{|l|}{ Tumor resection } \\
\hline total & & 25 & \\
\hline subtotal & & 2 & \\
\hline biopsy & & 1 & \\
\hline \multicolumn{4}{|l|}{ Histology } \\
\hline WHO I & & 1 & \\
\hline WHO II & & 25 & \\
\hline WHO III & & 2 & \\
\hline \multicolumn{4}{|l|}{ Jobs before treatment } \\
\hline Physical work & 8 & 8 & 0.3 \\
\hline Office work & 4 & 6 & 1.0 \\
\hline Intellectual work & 6 & 9 & 1.0 \\
\hline House-maker & & 4 & 0.1 \\
\hline incapacitated & & 1 & 1.0 \\
\hline
\end{tabular}

Table 1. Patients characteristics of conservatively and surgically treated patients.

$18(64.3 \%)$ males. The tumor was located in the cervical spine in $13(46.4 \%)$ patients, in the thoracic spine in 12 (42.9\%) patients, in the cervicothoracic region in two (7.1\%) patients and in the conus medullaris in one (3.6\%) patient. The intramedullary spinal cord ependymoma affected one spinal cord level in 20 and more than one level in 8 patients. The predominant symptoms, which lead to admission, were pain and paresthesia in $13(46.4 \%)$ cases, pain without sensory deficit in five (17.9\%) cases, paresthesia without further signs in four (14.3\%) patients, mild motor dysfunction in three (10.7\%) patients and incidental finding in one $(7.1 \%)$ patient. Clonus as pathological finding was present in one patient (7.1\%) and dyssynergia in another patient $(7.1 \%)$. Total resection of the tumor could be achieved in $25(89.3 \%)$ cases and subtotal resection in two cases (7.1\%). Mere biopsy of the lesion was performed in only one case (3.6\%).

Histological workup after surgery revealed WHO I ependymoma in only one (3.6\%) patient, WHO III in two (7.1\%) patients and WHO II in $25(89.3 \%)$ cases. The median modified McCormick score in surgically treated patients at admission was $1 \pm 0.38$ (SD) and according to the modified Rankin Scale all patients were in good functional condition (mRs 0-2), which indicates functionally independency, Fig. 1.

Compared to initial neurological status 9 patients remained unchanged postoperatively, of which three patients improved and one patient deteriorated at the last follow-up. Postoperative neurological decline was seen in 19 patients, of which 6 patients improved and 5 patients remained unchanged in further clinical course. 


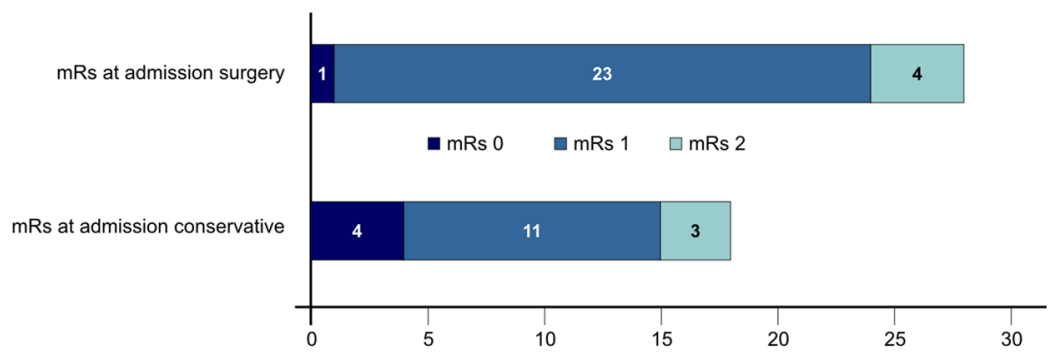

Figure 1. Modified Rankin Scale (mRs) at admission in surgically and conservatively managed patients at admission.

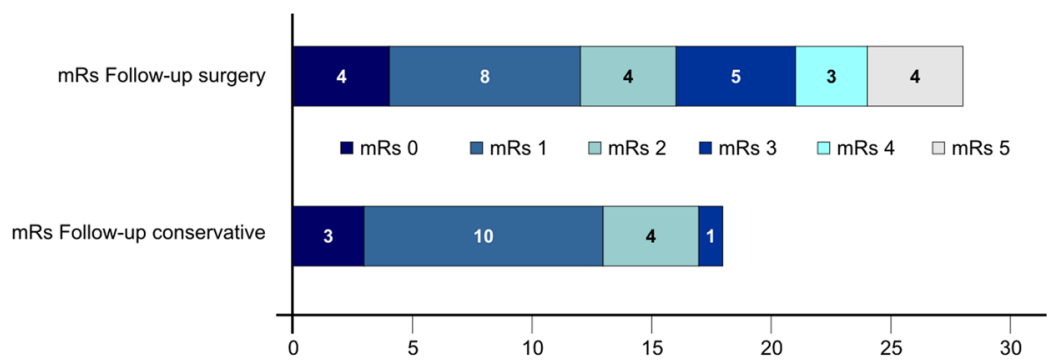

Figure 2. Modified Rankin Scale (mRs) at admission in surgically and conservatively managed patients in follow-up.

\begin{tabular}{|l|l|l|l|}
\hline & $\begin{array}{l}\text { Conservatively } \\
\text { managed }\end{array}$ & $\begin{array}{l}\text { Surgically } \\
\text { treated }\end{array}$ & P value \\
\hline mMcC at admission (median) & 1 & 1 & 1.0 \\
\hline mMcC at last follow up (median) & 1 & 2.5 & 0.001 \\
\hline mRS 0-2 at admission & $100 \%$ & $100 \%$ & 1.0 \\
\hline mRS 0-2 at last follow up & $94 \%$ & $57 \%$ & 0.007 \\
\hline Return to work & 15 & 10 & 0.002 \\
\hline
\end{tabular}

Table 2. Functional outcome at admission and at last follow up.

After a median follow-up time of 81.8 months the median McCormick score in surgically treated patients was $2.5 \pm 1.4, p=0.001$. Functional independency (mRs $0-2$ ) could be proved in 16 patients $(57.1 \%)$ as compared to $100 \%$ initially, $p=0.0001$ Fig. 2 .

Tumor recurrence as reason for clinical deterioration could be excluded in all cases. Eight patients (28.6\%) performed physical work, nine patients (32\%) had intellectual work, six (21.4\%) patients performed office jobs, four patients (14.3\%) were housewives and one patient was incapacitated.

At the last follow-up only 10 (35.7\%) patients returned to work. From further 18 patients undergoing surgical tumor resection and not returning to work after surgery, five patients had an office jobs prior to surgery, four were housemakers, intellectual work were performed in four cases and physical work in four cases. One patient could not work prior to surgery in order to incapacity and remained unemployment, Table 2.

Conservative group. At the time of first of introduction to our department 18 from 23 patients were employed. The median age in this group was $47.5 \pm 10.5$ years. There was an equal gender distribution consisting of nine females and nine males. The most affected spinal cord region in this group was the cervical spine in 12 $(66.7 \%)$ cases, followed by the thoracic region in six $(33.3 \%)$ cases. The tumor involved one level of the spinal cord in $14(77.7 \%)$ patients, two levels in three (16.7\%) cases and three levels in one (5.6\%). At first presentation only one patient revealed moderate motor dysfunction, whereas the main leading symptoms were dysesthesia and pain. Incidental finding as result of headache workup was the reason for initial introduction in four $(22.2 \%)$ patients, Table 3.

The median modified McCormick score at presentation in these patients was $1 \pm 0.4$ (SD) and the modified Rankin Scale consisting of $0-2$ was $100 \%$, Fig. 1. Over time a decline in the neurological function was found in three $(16.7 \%)$ patients, whereas only one patient revealed severe ataxia. Two of the three patients underwent surgery. Tumor progression detected on follow-up MRI was seen in one patient undergoing surgery, whereas the other one revealed a clinical deterioration, in the form of dysesthesia. The clinical decline in the third patient was 


\begin{tabular}{|l|l|l|l|l|l|l|l|l|}
\hline Patients & $\begin{array}{l}\text { Age } \\
\text { (years) }\end{array}$ & Sex & $\begin{array}{l}\text { Duration of } \\
\text { symptoms (months) }\end{array}$ & $\begin{array}{l}\text { mMcC at } \\
\text { admission }\end{array}$ & $\begin{array}{l}\text { mMcC at } \\
\text { last FU }\end{array}$ & $\begin{array}{l}\text { mRS at } \\
\text { admission }\end{array}$ & $\begin{array}{l}\text { mRS at } \\
\text { last FU }\end{array}$ & $\begin{array}{l}\text { Radiological } \\
\text { progression }\end{array}$ \\
\hline 1 & 47 & F & 4 & 2 & 2 & 2 & 2 & \\
\hline 2 & 55 & M & 4 & 1 & 3 & 1 & 3 & Yes \\
\hline 3 & 34 & F & 3 & 1 & 1 & 1 & 1 & \\
\hline 4 & 54 & F & 48 & 1 & 1 & 1 & 1 & \\
\hline 5 & 58 & F & 5 & 2 & 2 & 1 & 1 & \\
\hline 6 & 62 & M & 12 & 1 & 2 & 1 & 2 & No \\
\hline 7 & 50 & M & 2.5 & 1 & 1 & 1 & 1 & \\
\hline 8 & 53 & F & 1 & 2 & 2 & 2 & 2 & \\
\hline 9 & 51 & F & & 1 & 1 & 0 & 0 & \\
\hline 10 & 46 & M & 48 & 2 & 2 & 2 & 2 & \\
\hline 11 & 28 & M & 6 & 1 & 2 & 1 & 1 & No \\
\hline 12 & 51 & F & & 1 & 2 & 0 & 1 & \\
\hline 13 & 38 & F & & 1 & 1 & 0 & 0 & \\
\hline 14 & 26 & M & 1 & 1 & 0 & 0 & \\
\hline 15 & 55 & F & 1 & 1 & 1 & 1 & 1 & \\
\hline 16 & 59 & M & 8 & 1 & 1 & 1 & 1 & \\
\hline 17 & 48 & M & 3 & 1 & 1 & 1 & 1 & \\
\hline 18 & 40 & M & 3 & 1 & 1 & 1 & 1 & \\
\hline
\end{tabular}

Table 3. Demographics and clinical outcomes of 18 patients undergoing conservative management. FU: follow-up.

little, mild increase of paresthesia, and did not justify surgical intervention. The median modified McCormick score after a median follow-up period of 53.5 months was $1.0 \pm 0.6, p=0.1$. The modified Rankin Scale in one patient was 3 and in all other patients remained between $0-2(94.4 \%), p=1$ Fig. 2.

From 18 patients 15 patients $(83.3 \%)$ remained employed at the last follow up. The reason for unemployment was neurological detoriation in one patient and two patients (11.1\%) did not feel like working again and intended to apply for disability pension. Eight patients (44.4\%) performed physical work, six patients (33.3\%) had intellectual work, four $(22.2 \%)$ patients performed office jobs and five patients $(27.7 \%)$ were retired. All three patients, who did not return to work performed physical work.

Intergroup comparison. No significant differences were obtained analyzing number of investigated patients, mean age, gender distribution, length of follow-up, location and number of involved levels affected by the tumor. The different professional activities were almost similar in both groups, as well. Paresthesia was more often proven in the conservative group ( 11 vs. $4, \mathrm{p}=0.002)$ and pain in combination with paresthesia in the surgical group ( 0 vs. $13, \mathrm{p}=0.005$ ).

The median modified McCormick score between surgically and conservatively treated patients at admission did not differ significantly and was $1 \pm 0.4$ and $1 \pm 0.38$ in both groups, respectively, $p=1.0$. At last follow-up there was a decline in neurological function in surgically treated patients as assessed by the $\mathrm{mMcC}(1.0 \pm 0.6 \mathrm{vs}$. $2.5 \pm 1.4, p=0.001$ ), Table 2. The level of independency and good neurological function was assessed using the modified Rankin Scale and was defined between 0-2. At first admission 100\% of conservatively and surgically treated patients were ranked between $\mathrm{mRs}$ 0-2. At last follow-up there was a decline in neurological function in both groups. $94 \%$ of conservatively managed patients revealed a neurological status according to $\mathrm{mRs} 0-2$, whereas only $57 \%$ of surgically treated patients were functionally independent and ranked between $\mathrm{mRs} 0-2$ ( $p=0.007$ OR 12.75, CI 1.5-109.6).

At first admission 18 patients of conservatively managed patients and 28 patients of surgically treated patients were employed, $p=0.7$. At last follow-up after a median follow-up time of 81.8 and 53.5 months, respectively, 15 $(83 \%)$ of conservatively and $10(36 \%)$ of surgically treated patients returned to work, $\mathrm{p}=0.002$ OR 9, CI 2.1-38.8, Table 2.

Focusing on patients with a long follow-up period ( $>4$ years) there were 19 patients in the surgical arm and 9 patients in the conservative arm. The median initial neurological status according to the mMcC were $2 \pm 0.5$ and $1 \pm 0.4$, respectively and did not differ significantly, $p=0.1$. All patients in both arms were employed at initial presentation. At the last follow-up the $\mathrm{mMcC}$ in both groups were $2 \pm 1.4$ and $1 \pm 0.7, p=0.01$ and $9(47 \%)$ patients undergoing surgery vs 8 (89\%) patients being treated without surgery returned to work, $p=0.05$.

\section{Discussion}

Intramedullary spinal cord ependymoma is a rare entity accounting for $60 \%$ of all intramedullary spinal cord neoplasms $\mathrm{s}^{7,9,10}$. Despite increasing understanding of the disease, radiological imaging progress, wide access and availability of electrophysiological monitoring and improved microsurgical techniques the surgical removal of intramedullary ependymoma still remains challenging. Neurological deterioration after tumor removal remains a considerable disadvantage in patients. Conservative management of these patients has been described only once consisting of a single center case series ${ }^{11}$. In addition, until now no scientific data exist describing the ability to return to work after diagnosis and therapy of intramedullary spinal cord ependymoma. Aim of the present study 
is to elucidate the level of independency and moreover the work capacity after surgical and conservative treatment of intramedullary spinal cord ependymoma.

The role of work in our modern societies has become a central feature of economic and social life.

In addition, work can be seen as a source of socializing, self-confidence, physical and mental health and self-worth. Therefore, it is a crucial issue to evaluate the level of disability and work ability as indicator of successful treatment. Hence, many authors provided case series describing the functional outcome and resumption of work in many diseases, such as subarachnoid hemorrhage, glioma surgery, spine surgery, traumatic brain injury, nerve and plexus injury ${ }^{12-17}$.

The diagnosis of intramedullary spinal cord lesion has an enormous impact on patient's life, level of present or upcoming disability and ability to continue to work. Despite the benign character of the lesion, the potential compression of the spinal cord leads in many cases to severe disability. In many cases surgery is advocated and also performed, but reviewing the current published data the risk of permanent disability is accounting between $3 \%$ and $50 \%{ }^{6,7,18-21}$.

Even after complete tumor removal, good clinical condition after surgery and without proven tumor recurrence many patients reveal a decline in their neurological status induced more likely by microstructural atrophic changes within the spinal cord tissue ${ }^{18}$. Another issue is the lack of data concerning the functional outcome of conservatively managed patients. All together lead to the conclusion that the most appropriate therapy of intramedullary spinal cord lesions remains still challenging and that a multidisciplinary approach should be undertaken with consideration of neurological outcome and good quality of life.

Nevertheless, the mainstay of treatment of patients harboring symptomatic intramedullary spinal cord ependymoma is the microsurgical resection of the lesion. According to our institutional standard, patients with newly diagnosed symptomatic intramedullary spinal cord ependymoma were counseled for surgery. Surgery was indicated and recommended in all patients with neurological deficits, such as motor dysfunction, sensory deficit or bowl and bladder impairment. Moreover, there were two time periods how surgical intervention and conservative surveillance were recommended. In the beginning (1980-2000) surgery was recommended in all cases on initial presentation according to the pertaining view of treatment in these patients published by many authors. Conservative treatment was initially established in patients denying surgical treatment. All these patients underwent follow-up MRI and clinical examination to detect any changes in their clinical course. After having a group of patients, who primarily refused surgery, we found that these patients had a stable follow-up without progression of the disease. Thereafter, in some patients without neurologic deficit conservative management was recommended as well in accordance to our own institutional "experience".

After 2000 radiological surveillance was recommended as well and surgery was then performed in cases of tumor progression and neurological decline.

Therefore, we were able to evaluate the clinical outcome in these patients. Based on the results discussed above and in knowledge of surgery-related morbidity in patients with intramedullary spinal cord ependymoma, surgery might not be necessarily recommended in all patients. In some cases, especially presenting with mild or no symptoms conservative management can be an alternative, as well. But, in our patient's cohort two patients must undergo surgery in the follow up period due to neurological deterioration in order of tumor growth over time.

One aspect of good clinical outcome is the ability to return to work, which is not highlighted in this patient's population. By comparing the basic patient's characteristics and without identification of significant differences with regard to sex, age, affected spinal cord location of the lesion and involved spinal cord level, we could demonstrate that both groups are almost similar. We could also show that the initial neurological status at first introduction was similar, as well, which is the main aspect in case of detecting any differences affecting quality of life and work capacity over time. In our investigated patients population there was a significant difference in clinical outcome in patients undergoing surgical resection of their spinal cord lesions and that significantly more patients managed conservatively could return to work.

Study limitation. This study is limited by its retrospective design. Due to the benign entity intramedullary spinal cord ependymoma have a slow growth tendency. Therefore, it is mandatory to assess the clinical course of patients with a long follow-up period. Although most patients in our study had a long follow-up period, there were some patients with a relatively short follow-up. A longer follow-up period with serial imaging would have been useful to get some measure of the biology and natural history of these tumors.

\section{Conclusion}

Return to work or remaining employed is an important issue of good quality of life. The majority of patients, who underwent conservative management, revealed a stable functional status in the long term follow up and could significantly more often resume their working activity.

\section{Material and Methods}

Retrospective, single center review of all patients with intramedullary spinal cord ependymoma treated between 1980 und 2017. The neurological outcomes pre- and postoperatively and in conservatively managed patients, as well as long-term follow-up, were assessed using the modified McCormick Disability Scale (mMcC) and modified Rankin Scale. Diagnosis in conservatively treated patients based on MRI scan that were rated by both an experienced radiologist and the senior author as being consistent with an intramedullary spinal cord ependymoma in conservatively treated patients. Surgery was performed using a standard dorsal approach with laminectomy. In selected cases with multilevel tumor involvement a laminoplasty was performed instead. The amount of tumor resection was rated as total resection, subtotal resection or biopsy. Total tumor resection was defined as $100 \%$ tumor removal, if confirmed by the surgeon and postoperative MRI scan. 
Good outcome was defined as stable $\mathrm{mMcC}$ score or improvement in $\mathrm{mMcC}$ score in comparison to the condition at admission. According to the pertaining treatment recommendation surgery was advocated and performed in patients with assumed diagnosis of IMSCE in our department, as well. In cases of asymptomatic or mild symptomatic tumors and in knowledge of potential occurrence of neurological disability after surgery some patients refused surgery and advocated routinely MRI and follow-up examination. All these patients underwent further clinical and radiological follow-up. In cases of symptom progression or tumor growth over time surgery was recommended also in patients being initially treated conservatively. The primary outcome measure was the shift in the degree of disability among patients as measured by the modified Rankin Scale (mRS) (with scores ranging from 0 [fully independent] to 6 [dead]) at follow up and McCormick score (with scores ranging from 1 [neurologically intact] to 5 [paraplegia, quadriplegia], as well. Routinely performed electrophysiological examination was analyzed to detect neurological deterioration within the follow up period ${ }^{11}$.

Statistical analysis. All statistics were performed using SPSS (version 21, IBM, Armonk, New York). Significant values were considered to be $\mathrm{P}<0.05$. Comparison of important differences between the study groups was made using Fishers exact test for categorical variables. Nonparametric tests included the Mann-Whitney U and Kruskal-Wallis test to compare groups of data that did not follow the normal distribution. Tests for normality were performed using the Shapiro-Wilk test.

Ethical approval and informed consent. This study was approved by the local ethics committee of the Goethe University Frankfurt am Main, the methods were carried out in accordance with the relevant guidelines and regulations. Informed consent was obtained in each case.

\section{Data availability}

The datasets generated during and/or analysed during the current study are available from the corresponding author on reasonable request.

Received: 30 August 2019; Accepted: 23 January 2020;

Published online: 11 February 2020

\section{References}

1. Claudia Gaspar, D. H. Bedeutung der Arbeit Ein Kooperationsprojekt von GfK Verein und Bertelsmann Stiftung (2015).

2. Stergiou-Kita, M. et al. Qualitative meta-synthesis of survivors' work experiences and the development of strategies to facilitate return to work. Journal of cancer survivorship: research and practice 8, 657-70 (2014).

3. Asher, A. L. et al. An analysis from the Quality Outcomes Database, Part 2. Predictive model for return to work after elective surgery for lumbar degenerative disease. Journal of neurosurgery. Spine 27, 370-381 (2017).

4. Lee, S.-H. et al. Long-term outcomes of surgical resection with or without adjuvant radiation therapy for treatment of spinal ependymoma: a retrospective multicenter study by the Korea Spinal Oncology Research Group. Neuro-oncology 15, 921-9 (2013)

5. Karikari, I. O. et al. Impact of tumor histology on resectability and neurological outcome in primary intramedullary spinal cord tumors: a single-center experience with 102 patients. Neurosurgery 68, 188-97; discussion 197 (2011).

6. Kucia, E. J., Bambakidis, N. C., Chang, S. W. \& Spetzler, R. F. Surgical technique and outcomes in the treatment of spinal cord ependymomas, part 1: intramedullary ependymomas. Neurosurgery 68, 57-63; discussion 63 (2011).

7. Aghakhani, N. et al. Intramedullary spinal ependymomas: analysis of a consecutive series of 82 adult cases with particular attention to patients with no preoperative neurological deficit. Neurosurgery 62, 1279-85; discussion 1285-6 (2008).

8. Li, T.-Y. et al. Surgical strategies and outcomes of spinal ependymomas of different lengths: analysis of 210 patients: clinical article. Journal of neurosurgery. Spine 21, 249-59 (2014).

9. Malis, L. I. Intramedullary spinal cord tumors. Clinical neurosurgery 25, 512-39 (1978).

10. Abdullah, K. G. et al. Progression free survival and functional outcome after surgical resection of intramedullary ependymomas. Journal of clinical neuroscience: official journal of the Neurosurgical Society of Australasia 22, 1933-7 (2015).

11. Behmanesh, B. et al. Natural history of intramedullary spinal cord ependymoma in patients preferring nonoperative treatment. Journal of neuro-oncology 135, 93-98 (2017).

12. Stranjalis, G. et al. Elevated serum S-100B protein as a predictor of failure to short-term return to work or activities after mild head injury. Journal of neurotrauma 21, 1070-5 (2004).

13. Nishino, A. et al. Resumption of work after aneurysmal subarachnoid hemorrhage in middle-aged Japanese patients. Journal of neurosurgery 90, 59-64 (1999).

14. Asher, A. L. et al. 148 Predictive Model for Return to Work After Elective Surgery for Lumbar Degenerative Disease: An Analysis From National Neurosurgery Quality Outcomes Database Registry. Neurosurgery 63(Suppl 1), 160 (2016).

15. Mandonnet, E. et al. Initial experience using awake surgery for glioma: oncological, functional, and employment outcomes in a consecutive series of 25 cases. Neurosurgery 76, 382-9; discussion 389 (2015).

16. Kretschmer, T. et al. Patient satisfaction and disability after brachial plexus surgery. Neurosurgery 65, A189-96 (2009).

17. Steinmetz, M. P., Patel, R., Traynelis, V., Resnick, D. K. \& Anderson, P. A. Cervical disc arthroplasty compared with fusion in a workers' compensation population. Neurosurgery 63, 741-7; discussion 747 (2008).

18. Behmanesh, B. et al. Regional spinal cord atrophy is associated with poor outcome after surgery on intramedullary spinal cord ependymoma: a new aspect of delayed neurological deterioration. World neurosurgery, https://doi.org/10.1016/j.wneu.2017.01.026 (2017).

19. Chang, U. K., Choe, W. J., Chung, S. K., Chung, C. K. \& Kim, H. J. Surgical outcome and prognostic factors of spinal intramedullary ependymomas in adults. Journal of neuro-oncology 57, 133-9 (2002).

20. Klekamp, J. Spinal ependymomas. Part 1: Intramedullary ependymomas. Neurosurgical focus 39, E6 (2015).

21. Klekamp, J. Treatment of intramedullary tumors: analysis of surgical morbidity and long-term results. Journal of neurosurgery. Spine 19, 12-26 (2013).

\section{Author contributions}

B.B. study enrollment, data collection, writing and formatting manuscript, submission. F.G. data collection, interpretation of the data. S.W. data collection, follow-up examination. D.D. data collection, follow-up examinations. J.W. data collection. L.I. analyzing the data. V.S. Supporting, supervising the study. G.M. Supervising the study, senior surgeon. 


\section{Competing interests}

The authors declare no competing interests.

\section{Additional information}

Correspondence and requests for materials should be addressed to B.B.

Reprints and permissions information is available at www.nature.com/reprints.

Publisher's note Springer Nature remains neutral with regard to jurisdictional claims in published maps and institutional affiliations.

(c) (i) Open Access This article is licensed under a Creative Commons Attribution 4.0 International License, which permits use, sharing, adaptation, distribution and reproduction in any medium or format, as long as you give appropriate credit to the original author(s) and the source, provide a link to the Creative Commons license, and indicate if changes were made. The images or other third party material in this article are included in the article's Creative Commons license, unless indicated otherwise in a credit line to the material. If material is not included in the article's Creative Commons license and your intended use is not permitted by statutory regulation or exceeds the permitted use, you will need to obtain permission directly from the copyright holder. To view a copy of this license, visit http://creativecommons.org/licenses/by/4.0/.

(c) The Author(s) 2020 